\title{
Temporal properties of aftershock sequences of large earthquakes in Iran - Analysis of primary and secondary aftershocks of the Ezgeleh sequence
}

\author{
Mahdieh Lavasani ${ }^{1}$ and Elham Shabani ${ }^{*, 2}$ \\ (1) $\mathrm{PhD}$ student, Institute of Geophysics, University of Tehran, Iran \\ (2) Department of Seismology, Institute of Geophysics, University of Tehran, Iran
}

Article history: received August 5, 2019; accepted June 9, 2020

\begin{abstract}
In this study, the decay of earthquake aftershock sequences of some major earthquakes in different tectonic regimes in the Iranian plateau is discussed. The studied earthquakes are Rigan [2010], Ahar-Varzaghan [2012], Goharan [2013], Sefidsang [2017] and Ezgeleh [2017]. The spatial and temporal windows are considered based on the method proposed by Gardner and Knopoff [1974] to compute decay parameters for each sequence. The decay rates of sequences were compared to well-known models to find the best fit for each sequence. The results showed that the modified Omori is the best fit for Ahar-Varzaghan and Ezgeleh sequences, for Rigan and Sefidsang sequences the modified Omori and the Kisslinger ones found as the best fits. The values of the $p$ parameter of the Reasenberg and Shcherbakov models were larger compared to the Omori model, but the parameter of the Kisslinger model was slightly smaller compared to the Omori one. The $c$ parameter showed an inverse relation to the threshold magnitude. The correlation between the $p$ and $c$ parameters and also the and the Gutenberg and Richter (G-R) parameters were investigated. In addition, we made use of a graphical method to analyze the seismic sequence of the Ezgeleh earthquake during 13 months after the main event. The graphical method was successful to estimate the occurrence of an event with an approximate magnitude of $M=6.4$ in the sequence.
\end{abstract}

Keywords: Aftershock sequences, decay models, primary and secondary aftershocks, Iran, Ezgeleh.

\section{Introduction}

Seismic sequences are referred to as a series of earthquakes in a region that occur over a certain period of time. Typically, any seismic sequence consists of a main event and its associated events; foreshocks and aftershocks. The important parameters of any seismic sequence are the number of aftershocks, spatial distribution and the reduction of the number over time. The design of procedures for identifying and differentiating these stages in the seismic regime can help a better understanding of the earthquake phenomenon and consequently can reduce the impacts 


\section{Mahdieh Lavasani and Elham Shabani}

of earthquakes. Aftershock events are associated with smaller magnitudes and with a time interval of between several minutes to several years after the main seismic earthquake, and their abundance decreases over time [Omori, 1894].

Aftershocks can be affected by various factors. The simplest one could be considered as when the stress in a region increases, not all of the stress is released by the main event, but some part is released by aftershocks [Das and Scholz, 1981a, b]. The concentrations of stress resulting from asperities and barriers can create aftershocks [Scholz, 2002]. In some cases, the adjacent faults to the main events are broken down and can lead to aftershocks or more energetic events than the previous events. Of course, in some cases, seismic waves caused by the main event can lead to change the stress of the fluids into adjacent fault holes, which reduces the strength (static friction) on the adjacent faults and creates aftershocks [Shcherbakov et al., 2005]. Also, as stated by Riga and Balocchi [2017] the aftershocks are classified by Kisslinger [1996] into three sets: aftershocks occurring in the rupture area of the main fault plane, aftershocks occurring in the main fault plate, but outside the rupture area and aftershocks outside the main fault.

Aftershock studies are considered as a major step towards knowing better the physical process of earthquakes [Kisslinger, 1996]. Many studies are carried on the temporal and spatial distribution patterns of aftershocks. One of the oldest and most important researches in this regard is carried by Utsu [1969]. Also, Reasenberg [1989] studied the California earthquakes and presented a relation to combine the two experimental relationships of Gutenberg and Richter [1944] and Omori. Later, Kisslinger [1993] studied the dependence of the aftershock distribution on physical properties of fault zones and environmental conditions, especially resistance, stress and temperature. Then, Shcherbakov et al., [2004] presented a generalized formula for aftershock decay rates, by combining the three relations between the Omori law, the modified G-R and the modified Bath's law. Gasperini and Lolli [2009] performed a comparison between decay rate models in Southern California and Italy based on the modified Omori model, the modified Kisslinger model and the band limited power law. They resulted that the modified Kisslinger model and the band limited power law generally explain decay rate aftershocks better than the modified Omori model. More recent studies on the spatial and temporal analyses of the distribution of aftershock sequences carried on in different parts of the world; Wiemer and Katsumata [1999], Bayrak and Öztürk [2004], Öztürk et al. [2008], Nuannin et al. [2012] and Öztürk and Şahin [2019]. Ommi et al., [2016] determined the mean values of coefficients of the Omori law for 15 mainshock-aftershock sequences in different seismotectonic provinces of Iran. Also, Ansari [2017] studied the spatial and temporal seismicity parameters, stress state and seismic energy of the Shonbe earthquake sequence.

In this study, decay rates of the earthquake aftershock sequences of some major earthquakes in different tectonic regimes in the Iranian plateau were discussed. The studied earthquakes are introduced in Table 1. On 20 December 2010, a $M_{N}=6.5$ earthquake struck the region near to Rigan, in the Southeast of Iran, in the Makran zone. On 11 August 2012, two $M_{N}=6.5$ and $M_{N}=6.3$ earthquakes at 16:53 and 17:04 local times occurred in Varzeghan and Ahar regions in Alborz-Azarbayjan seismotectonic zone, known as the Ahar-Varzaghan doublet earthquakes. On 11 May 2013, a $M_{N}=6.1$ earthquake occurred near to Goharan village in the Makran zone. On 5 April 2017, a $M_{N}=6$ earthquake occurred near to Sefidsang in the Kopeh-Dagh zone. On 12 November 2017, a $M_{N}=7.3$ earthquake occurred in Ezgeleh, near to the Iran-Iraq border, in Zagros.

\begin{tabular}{cccccc} 
Earthquake studied & Rigan & $\begin{array}{c}\text { Ahar- } \\
\text { Varzaghan }\end{array}$ & Goharan & Sefidsang & Ezgeleh \\
Lat. $\left({ }^{\circ} \mathrm{N}\right)$ & 28.44 & 38.39 & 26.60 & 35.85 & 34.77 \\
\hline Long. $\left({ }^{\circ} \mathrm{E}\right)$ & 59.15 & 46.81 & 57.86 & 60.34 & 47.76 \\
\hline Mainshock magnitude $\left(M_{N}\right)$ & 6.5 & 6.5 & 6.1 & 6 & 7.3 \\
\hline Date of mainshock & $20 / 12 / 2010$ & $11 / 8 / 2012$ & $11 / 5 / 2013$ & $5 / 4 / 2017$ & $12 / 11 / 2017$ \\
\hline Depth $(\mathrm{km})$ & 13.3 & 9 & 14.5 & 6 & 18.1 \\
\hline Magnitude of the largest aftershock & 5.1 & 5.4 & 5.8 & 5.3 & 5.9 \\
\hline Date of the largest aftershock & $20 / 12 / 2010$ & $7 / 11 / 2012$ & $12 / 5 / 2013$ & $2 / 5 / 2017$ & $25 / 8 / 2018$ \\
\hline Number of aftershocks larger than $M_{C}$ & 59 & 2813 & 183 & 455 & 2095 \\
\hline Temporal window $($ days) & 61 & 61 & 54 & 54 & 81 \\
\hline Spatial window $(\mathrm{km})$ & 39 & 90 & 510 & 510 & 380 \\
\hline
\end{tabular}

Table 1. The parameters of the studied earthquakes. 
The primary purpose of this study is analyzing the decay rates for different sequences of some large earthquakes in Iran applying some well-known decay models. For the second purpose, we studied the dependence of the parameters of the Omori law on threshold magnitudes and temporal windows. Moreover, the first primary and secondary aftershocks are proposed for the most recent sequence of Ezgeleh 2017, applying a graphical method proposed by Riga and Balocchi [2016].

\section{Tectonic setting}

The Iranian plateau is located in the Alps-Himalayas seismic belt, one of the most active and seismic regions on the Earth, in the collision zone of the Arabian, Indian and Eurasian plates. The collision of these plates and the pressure they have caused deformations, cracks, mountains and earthquakes. The seismiotectonics of Iran were studied by individuals, including Berberian [1981] and Nowroozi [1976]. All have come to terms with the fact that the Iranian plateau contains different seismiotectonic regimes. In this study, we used seismiotectonic provinces proposed by Mirzaei et al., [1998]. They subdivided the Iranian plateau into five major seismotectonic provinces: Zagros, Alborz-Azarbayjan, Central-East parts, Kopeh-Dagh and Makran (Figure 1). Seismic parameters vary in these seismiotectonic provinces. The frequency of earthquakes is small in Alborz and central Iran, but return periods of earthquakes are long. In contrast, in Zagros the frequency of earthquakes is high and magnitudes of the earthquakes are small.

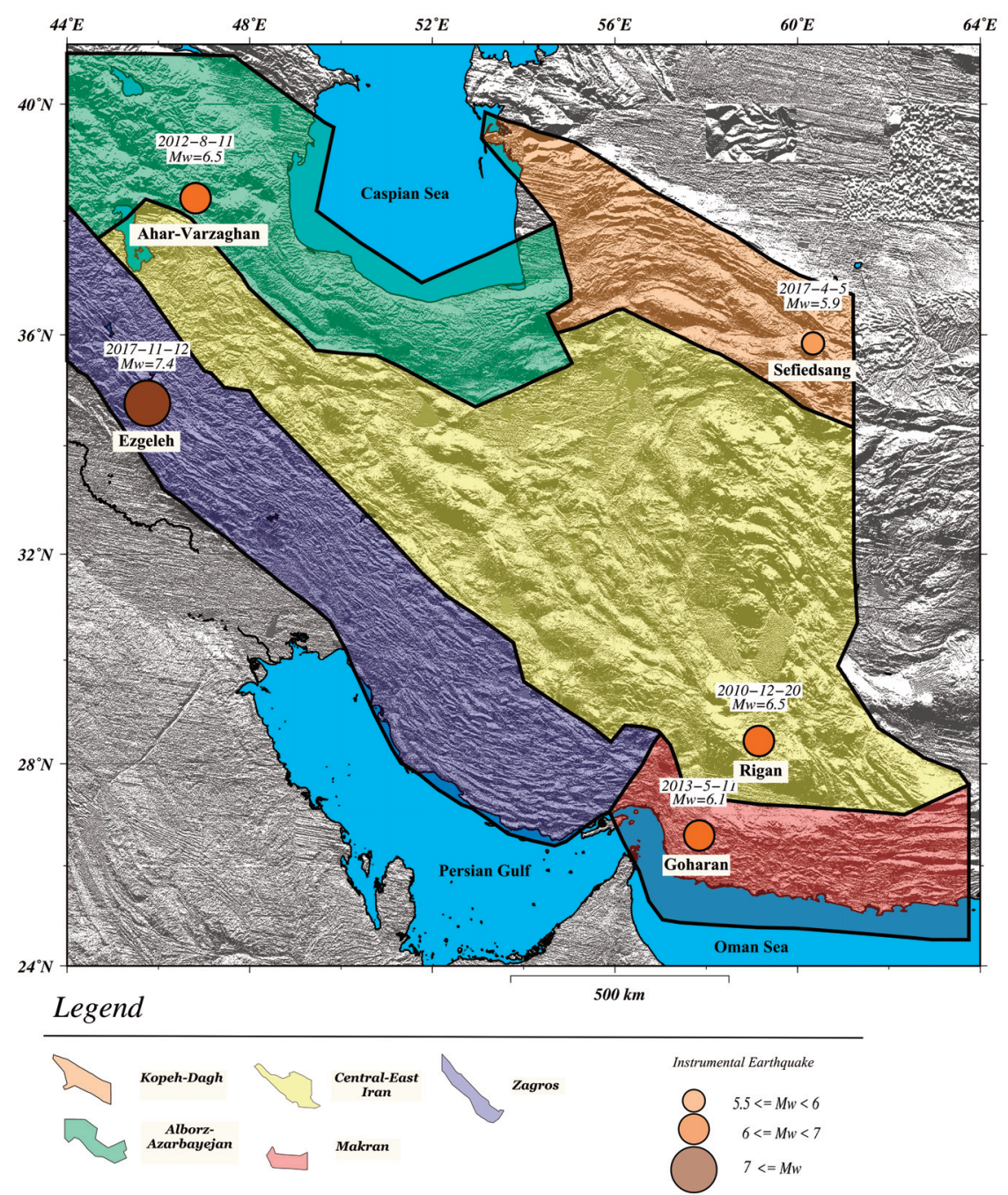

Figure 1. The Iranian seismotectonic provinces based on Mirzaei et al., (1998) and locations of the studied large earthquakes. 


\section{Mahdieh Lavasani and Elham Shabani}

\section{Decay models}

There are different methods for separating foreshocks, main shocks and aftershocks. Van Stiphout et al., [2012] made a complete review of different declustering algorithms. We applied the Gardner and Knopoff [1974] spatial and temporal windows. According to studies of Rezapour and Mohsenpur [2013] and Walker et al. [2013] the Rigan earthquake included two seismic sequences occurred on two cross-faults, we considered the first event in a period of 39 days before the second sequence was started. The Ahar-Varzaghan earthquake has a secondary sequence that occurred approximately 90 days after the main shock. The aftershocks migrated in both along-strike and up-dip directions [Rezapour, 2016]. We studied the Ahar-Varzaghan earthquake in a 90 days period, this is why the time windows of the two earthquakes mentioned are not accordance with the time windows in Gardner and Knopoff [1974], as presented in Table 2.

\begin{tabular}{ccc}
$\mathbf{M}$ & $\mathbf{L}(\mathbf{k m})$ & T (days) \\
2.5 & 19.5 & 6 \\
\hline 3 & 22.5 & 11.5 \\
\hline 3.5 & 26 & 22 \\
\hline 4 & 30 & 42 \\
\hline 4.5 & 35 & 83 \\
\hline 5 & 40 & 155 \\
\hline 5.5 & 47 & 290 \\
\hline 6 & 54 & 510 \\
\hline 6.5 & 61 & 790 \\
\hline 7 & 70 & 915 \\
\hline 7.5 & 81 & 960 \\
\hline 8 & 94 & 985 \\
\hline
\end{tabular}

Table 2. Aftershock identification windows (Gardner and Knopoff, 1974).

One of the most important factors in measuring seismic parameters is the threshold magnitude. The threshold magnitude is defined as the lowest magnitude at which $100 \%$ of the earthquakes in a space-time volume are detected [e.g. Mignan and Woessner, 2012]. This parameter was determined for different seismotectonic provinces of Iran by Mousavi et al. [2014] and Ommi et al. [2016]. In order to determine the spatial and temporal distributions of earthquakes, the seismic pattern, first the G-R law was investigated for each event and the $a, b$ and parameters were calculated applying the ZMAP package Wiemer [2001] as shown in Figure 2. The ZMAP software derives the best fitted model using the Akaike Information Criteria [Akaike, 1974], denoted as AIC, the best model corresponds to the model with lower AIC value. The parameters of the model are derived using the maximum likelihood using the likelihood over the time span of the sequence. We examined the impact of different values of threshold magnitudes and the behavior of their aftershock sequences is compared with different decay models; Omori [1894] which later modified by Utsu [1961], Reasenberg and Jones [1989], Kisslinger [1993] and Shcherbakov et al., [2004]. Then, the parameters and decay rates of the abovementioned sequences were discussed and analyzed. 

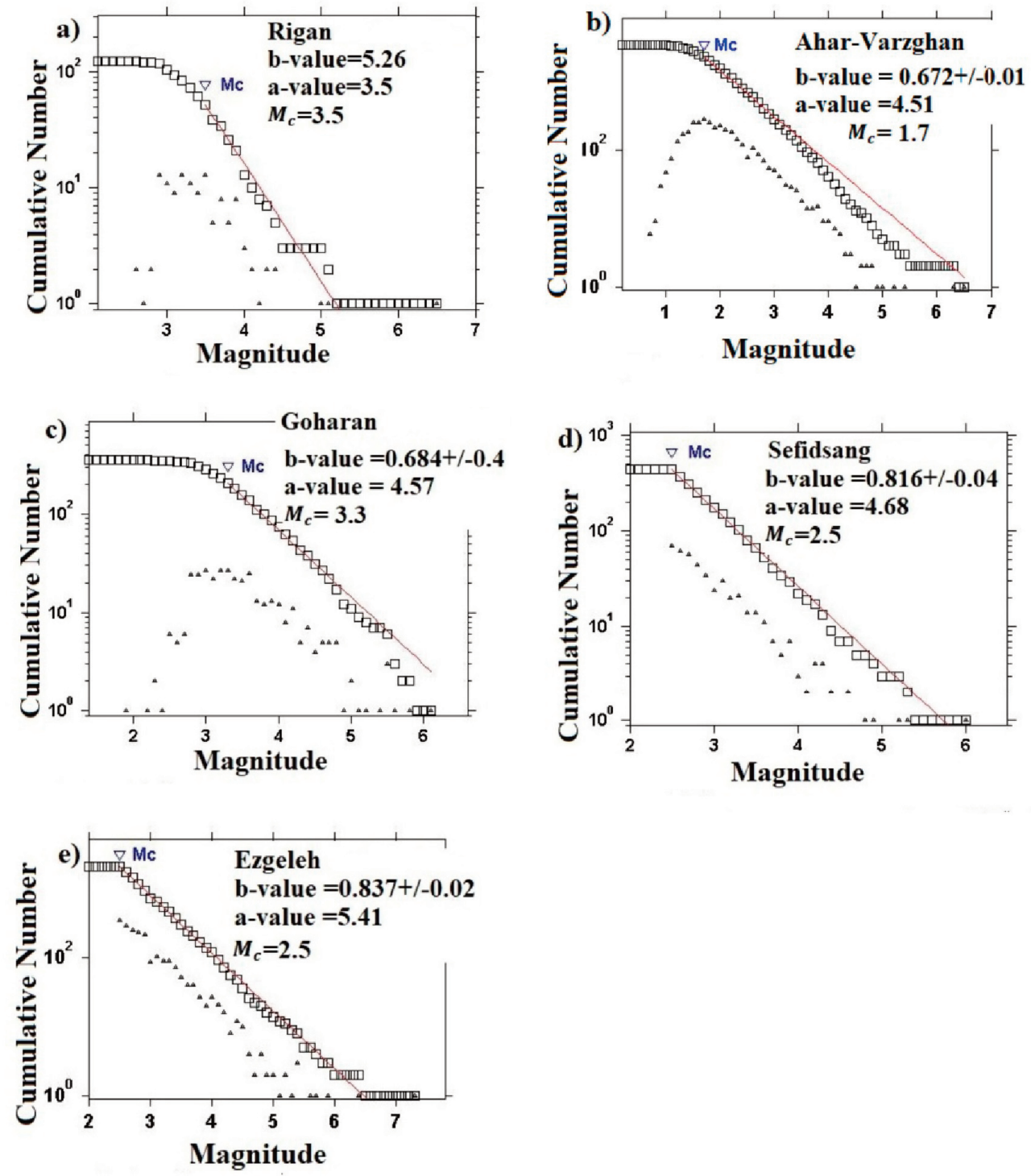

Figure 2. The threshold magnitude Mc, a and b values deduced for each earthquake.

There are two empirical laws that can be applied to the aftershock sequences;

1) The frequency-magnitude distribution of the aftershocks following a main event can be modeled by the G-R law as in relation (1);

$$
\log _{10} N(\geq m)=a-b m
$$

where $N$ is the number of earthquakes with magnitudes greater than or equal to $m$, and $b$ is the slope of the frequency-magnitude distribution.

2) The magnitude difference between a main event and its largest recorded aftershock according to the Bath's law [Bath, 1965] in relation (2) is:

$$
\Delta m=m_{m s}-m_{a s}^{\max },
$$

where $m_{m s}$ is the magnitude of the main event and $m_{a s}^{\max }$ is the magnitude of its largest recorded aftershock. 


\section{Mahdieh Lavasani and Elham Shabani}

The aftershock sequences are discussed based on different decay models (relations 3 to 7 ), and the relevant parameters are extracted. Relation (3) is the rate of aftershock occurrence in time $t$, follows the modified Omori law proposed by Utsu [1961] as

$$
n(t)=k(t+c)^{-p}
$$

where the $p$ parameter indicates the speed of the decay rate of aftershocks. Also, the slope of the graph decreases more rapidly with increasing the $p$ value, until the decay rate of the aftershock sequence reaches the background seismicity. It has been shown by Mogi [1967a, b] that the decreasing rate of aftershock activity $(p \geq 1.3)$ occurs in the regions where the crust is warmer. Additionally, changes in the $p$ value can be related to the degree of heterogeneity of the fault or the liquid fluid in the fault, which weakens and reduces the shear strength of the fault [Nur and Booker, 1971]. Areas that experience greater slip during the main event specify larger $p$ values. The c parameter represents the behavior of missing aftershocks in the early stage of an aftershock sequence. Mostly as in the initial stages of sequences of aftershocks the smaller events overlap on the seismogram or because the major earthquake faults have a large seismic motion and activity during the first hours, then the apparent reduction of small events near to epicenter locations, reduce in the very beginning times of the catalog of earthquakes. At this part, aftershocks seem not to follow a decreasing rule. The Omori $p$, c and $k$ parameters can be estimated by maximizing the loglikelihood function [Ogata, 1983; Utsu, 1995].

Reasenberg and Jones [1989] presented a parametric model for describing earthquake sequences based on the California earthquakes and the probability of occurring any larger earthquake or strong aftershocks. This model also presents a method for estimating the probability of occurrence of strong aftershocks or larger earthquakes at any time interval. The model is based on a nonhomogeneous Poisson process in time, that follows the modified Omori law, as well as the distribution of magnitudes that follow the G-R relation. Then, the decay rate, $\lambda$, of aftershocks with magnitude $M$ or larger, at time $t$ following the main event with magnitude $M_{m}$ is according to relation (4) as

$$
\lambda(t, M)=10^{\left[a+b\left(M_{m}-M\right)\right]}(t+C)^{-p}
$$

where $a, b, p$ and $C$ are constants.

On the other hand, Kisslinger [1993] applied the stretched exponential relaxation function, presented by Williams and Watts [1970], to the aftershocks. Kisslinger showed the decay rate of aftershock sequences follows to relation (5) as

$$
n(t)=q \mathrm{~N}^{*}(0) t^{(q-1)} t_{0}-q e^{-\left(\frac{t}{t_{0}}\right) q}
$$

where $\mathrm{N}^{*}(0)$ is a finite number of potential events at the beginning of the sequence, $t_{0}$ is the relaxation time for the overall process, which has not yet been related to a specific physical mechanism and $q$ is a coefficient that has a value of $0<q \leq 1$. Relation (5) is accepted as a valid universal function which it has been compatible with many aftershock sequences in the world. Then Kisslinger [1993] compared the relation (5) with the modified Omori law and by fixing the parameters to obey the modified Omori law, he revised it as in relation (6),

$$
n(t)=k^{\prime} t^{-p^{\prime}} e^{-\left(\frac{t}{t_{0}}\right)^{1-p^{\prime}}}
$$

Later Shcherbakov et al. [2004] modified the Bath's law, so that the largest aftershock was obtained by replacing $(\mathrm{N} \geq \mathrm{m})=1$ in the G-R relation. They proposed relation (7) which is a combination of the G-R relation, the Bath law and the Omori law as

$$
r(t, m)=\frac{(p-1) 10 b\left(m_{m s}-\Delta m s-m\right)}{c(m)} \frac{1}{\left[1+\frac{t}{c(m)}\right]_{p}}
$$

where $r(t, m)$ is the decay rate of occurrence of aftershocks with magnitudes greater than $m$ per day, $\Delta m^{*}$ is the modified Bath's law, $t$ is the time after the main event, $m_{m s}$ is the main event and $t$ and $c(m)$ are characteristic times. 


\section{Decay rates of large earthquakes in Iran}

The parameters of each decay rate are obtained based on the least square method. All seismological data were taken from the Iranian Seismological Center (IRSC), the magnitude reported by IRSC is $M_{N}$, a modified Nuttli magnitude. The decay rates of the studied earthquakes are shown in Figure 3 (a to e). The mean value of the $p$ parameter for the studied earthquakes for the primary aftershock, in the Omori law is 1.02, and in the Reasenberg, Kisslinger and Shcherbakov models are 6.48, 0.72, and 16.15, respectively. Due to the incomplete data for Rigan earthquake, the Shcherbakov $p$ parameter is not properly estimated. A summary of the results of decay rate models for the studied earthquakes is presented in Table 3, including the deduced R-square values.
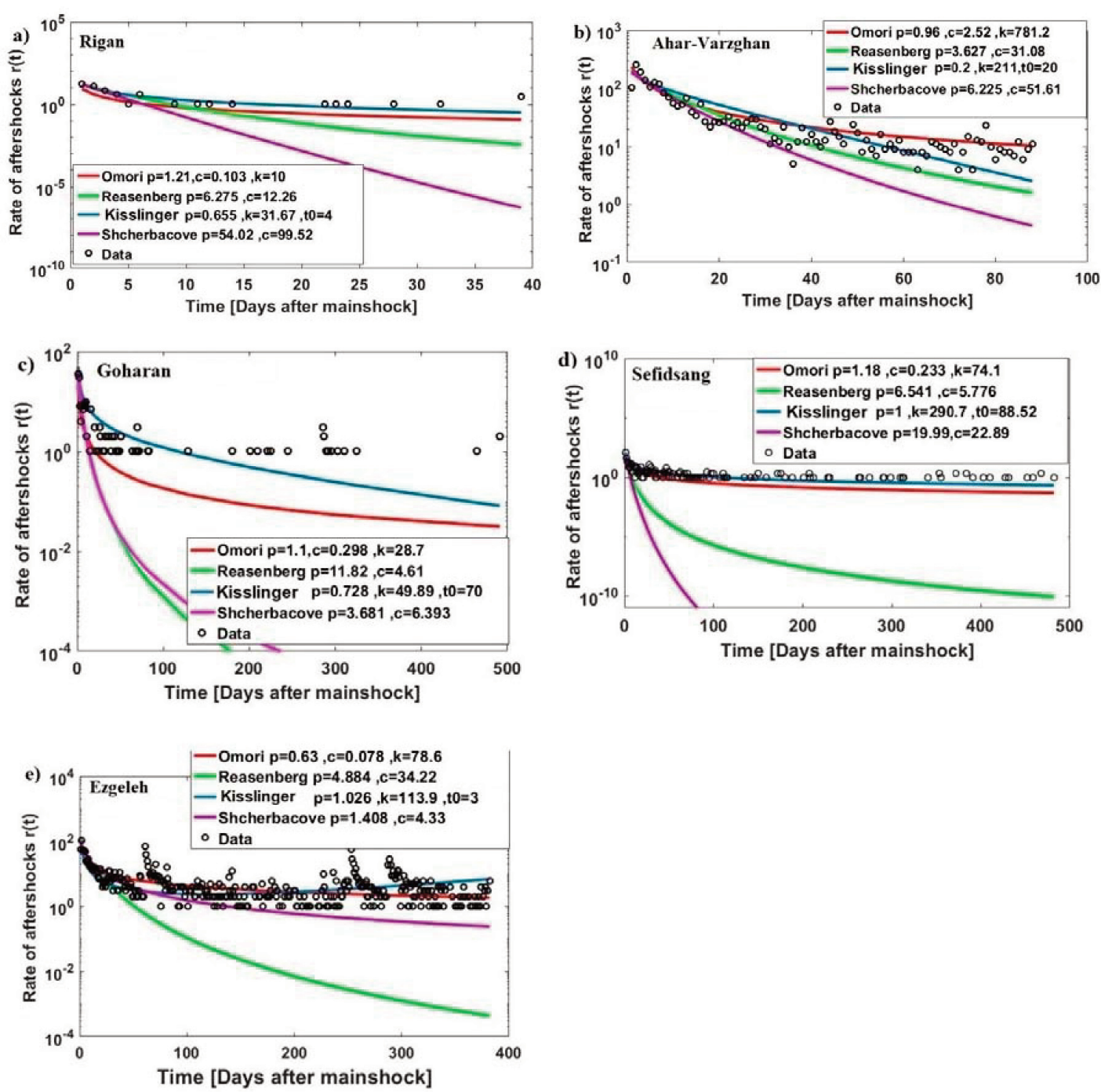

Figure 3. Comparisons of earthquake decay rates Omori, Reasenberg, Kisslinger and Shcherbakov for the studied earthquakes. 


\begin{tabular}{|c|c|c|c|c|c|c|}
\hline & Parameter & Rigan & $\begin{array}{c}\text { Ahar- } \\
\text { Varzaghan }\end{array}$ & Goharan & Sefidsang & Ezgeleh \\
\hline $\begin{array}{l}\text { Threshold } \\
\text { magnitude }\end{array}$ & $M_{c}$ & 3.2 & 1.7 & 3.3 & 2.5 & 2.5 \\
\hline \multirow{4}{*}{$\begin{array}{c}\text { Omori } \\
\text { (Cumulative } \\
\text { numbers) }\end{array}$} & $k_{1}$ & 10 & 781.2 & 28.7 & 74.1 & 78.6 \\
\hline & $p_{1}$ & 1.21 & 0.96 & 1.1 & 1.18 & 0.63 \\
\hline & $c_{1}$ & 0.10 & 2.52 & 0.3 & 0.22 & 0.08 \\
\hline & R-square & 0.37 & 0.56 & 0.82 & 0.81 & 0.34 \\
\hline \multirow{3}{*}{ Reasenberg } & $p$ & 6.27 & 3.63 & 11.82 & 5.78 & 4.88 \\
\hline & $c$ & 12.26 & 31.08 & 4.61 & 6.54 & 34.22 \\
\hline & R-square & 0.88 & 0.55 & 0.79 & 0.64 & 0.25 \\
\hline \multirow{4}{*}{ Kisslinger } & $k$ & 31.67 & 211 & 49.89 & 290.7 & 113.9 \\
\hline & $t$ & 0.65 & 0.2 & 0.73 & 1 & 1.0 \\
\hline & $t_{0}$ & 4 & 20 & 70 & 7 & 3 \\
\hline & R-square & 0.93 & 0.51 & 0.85 & 0.94 & 0.26 \\
\hline \multirow{3}{*}{ Shcherbakov } & $p$ & 54.02 & 6.22 & 3.11 & 19.99 & 1.41 \\
\hline & c & 99.52 & 51.61 & 5.25 & 22.89 & 4.33 \\
\hline & R-square & 0.40 & 0.20 & 0.78 & 0.63 & 0.29 \\
\hline
\end{tabular}

Table 3. A summary of the results of decay rate models for the studied earthquakes in Iran.

Also, Ommi et al. [2016] found the parameters of the Omori law for the Ahar Varzegan earthquake as $p=1.03$, $c=1.44, k=441$ for aftershocks greater than 1.8 during 724 days after the mainshock. Farahani [2018] found $p=0.95$, $c=0.037, k=12.79$, for aftershocks larger than 3.4 .

The speed of the decay rate has a direct relation with the energy drop of the main event. Therefore, the slope of decay rates of the aftershock sequences could be a proper criteria representative of evacuation of the stored energy. The dominant decay rate in this research is the Omori relation. The $k$ parameter, depends on the seismicity of the region. It is obvious that by increasing the threshold magnitude and shortening the temporal window, the $k$ parameter is decreased. For discussing about changes in the $p$ and $c$ parameters further examinations are required. According to some findings [e.g. Utsu, 1962; Ranalli, 1969; Yamakawa et al., 1969; Hamaguchi and Hasegawa, 1970], the $p$ and $c$ parameters are independent of the threshold magnitude $M_{c}$. There are also few researches [e.g. Utsu et al., 1995; Motoya and Kitagamae, 1971] showed the dependency of $p$ on $M_{c}$. We investigated the dependency of the $p$ and $c$ parameters for Rigan, Ahar-Varzaghan, Goharan, Sefidsang and Ezgeleh earthquakes. Figure 4 depicts the $p$ and $c$ parameters of the Omori law versus different threshold magnitudes, for the studied earthquakes. According to Figure 4, changes in the $p$ and $c$ parameters versus different magnitude thresholds are small for the mentioned earthquakes.

In order to investigate the impact of different time intervals of the seismic sequence on the parameters of models, different temporal windows are tested according to Table 4. There are slight changes in the values of the $p$ and $c$ parameters, particularly differences are obvious for 90 and 180 time windows in the Ezgeleh earthquake. 

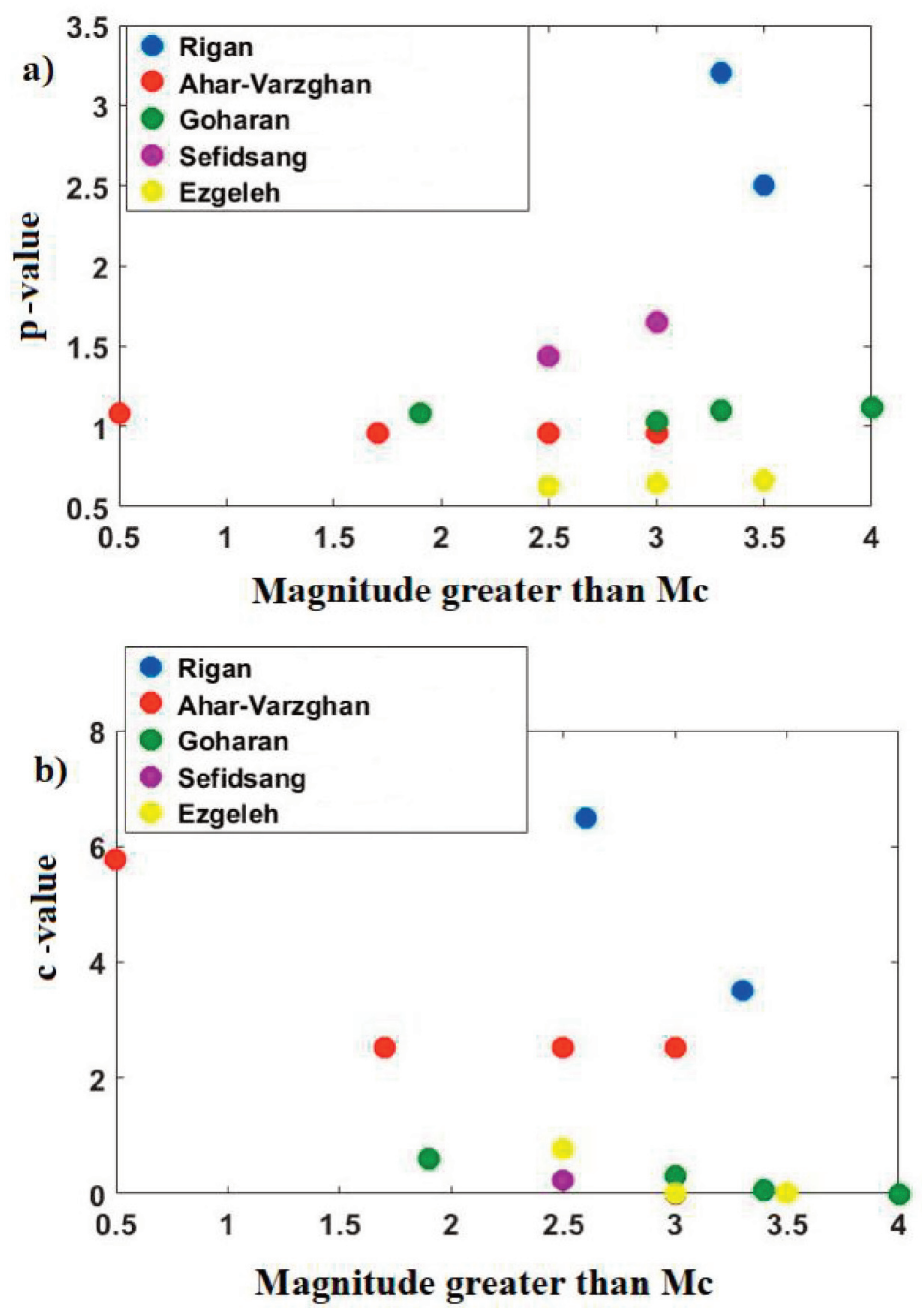

Figure 4. The changes of the Omori law parameters; $p$ and $c$ versus different threshold magnitudes for the studied earthquakes.

\begin{tabular}{ccccc} 
Earthquake & Temporal window (days) & Parameter $\boldsymbol{p}$ & Parameter $\boldsymbol{c}$ & Parameter $\boldsymbol{k}$ \\
\hline Goharan & 550 & 1.18 & 0.61 & 57.6 \\
\hline & 180 & 1.32 & 0.91 & 2 \\
\hline Sefidsang & 90 & 1.15 & 0.59 & 73.5 \\
\hline & 510 & 1.18 & 0.23 & 73.5 \\
\hline \multirow{2}{*}{ Ezgeleh } & 180 & 1.17 & 0.23 & 71.5 \\
\hline & 180 & 1.16 & 0.21 & 78.6 \\
\hline & 360 & 0.63 & 0.08 & 272.6 \\
\hline
\end{tabular}

Table 4. The percentage of relative differences between the parameters $p, c$ and $k$ vin different temporal windows. 


\section{Mahdieh Lavasani and Elham Shabani}

Also, the correlation between each couple of $p, c$ and $a$ parameters were studied for Goharan, Sefidsang and Ezgeleh earthquakes, the results are presented in Figure 5. Where the stars indicate the time period of 180 days and the plus signs are assigned to the time period of 90 days. According to Figure 5 , the correlation between $p$ and $c$ parameters also between $p$ and the G-R parameters for Goharan and Ezgeleh earthquakes are not constant over the time. The correlations between $p$ with $a, b, c$ parameters for different threshold magnitudes are not constant at different threshold magnitudes.
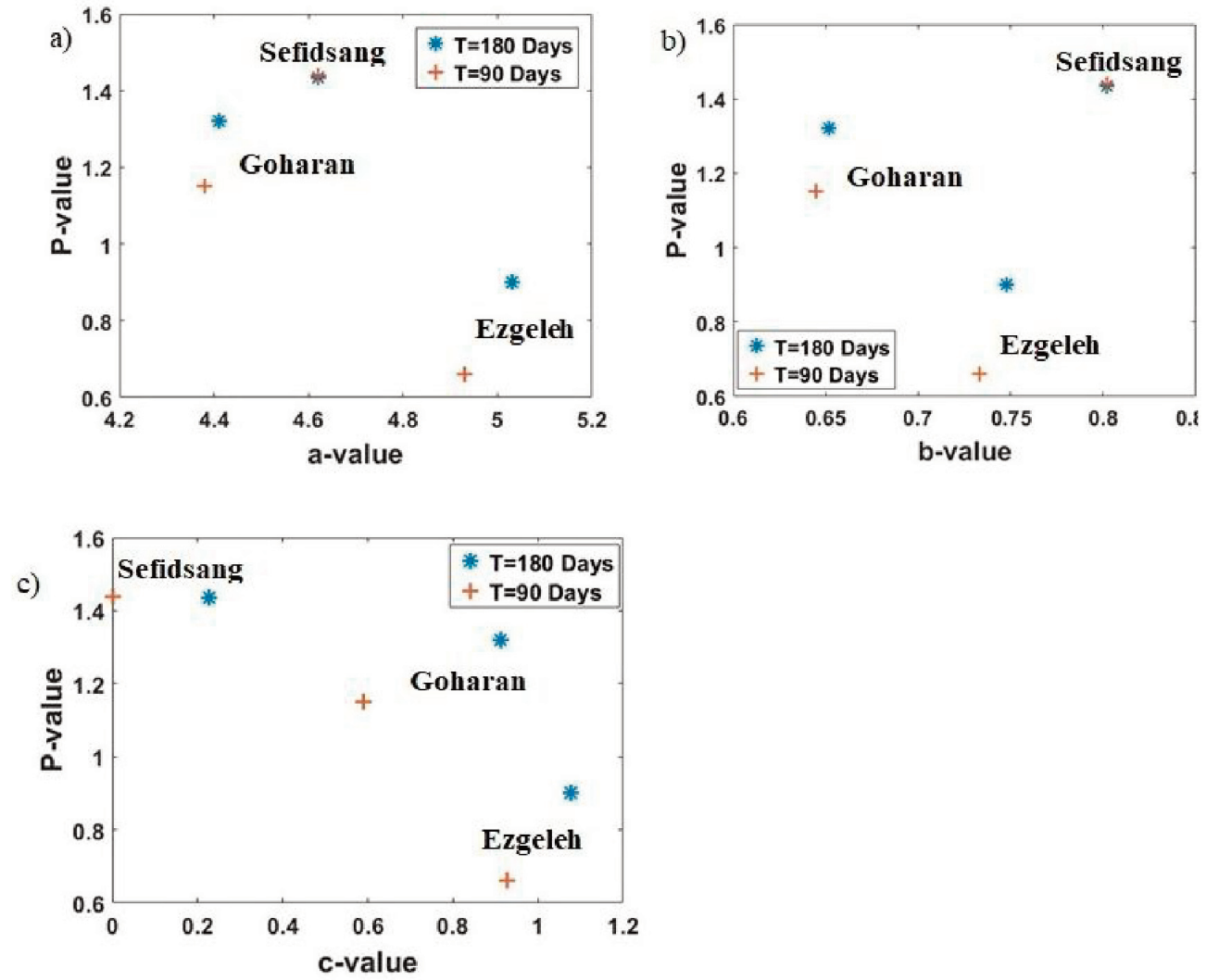

Figure 5. The correlations between parameters a) $p$ and $a$, b) $p$ and b, c) $p$ and $c$, in two time intervals 90 and 180 days.

\subsection{The primary and secondary aftershocks of the Ezgeleh earthquake}

The 2017 Ezgeleh earthquake of magnitude 7.3 occurred in a region where large earthquakes have not been documented for several centuries. Understanding fault locations, geometries, and seismic behaviors are highly noticeable in this region [Gombert et. al., 2019]. In this regard, we studied the sequence of the Ezgeleh. The epicenter and aftershocks of the Ezgeleh earthquake are depicted in Figure 6. Also the seismicity map of the region is presented in Figure 7. The type of aftershocks of the Ezgeleh earthquake is analyzed through the graphical method introduced by Riga and Balocchi [2017] and the primary and secondary aftershocks were distinguished. Figure 8 presents the branch structure for the Ezgeleh earthquake during 15 months; starting from three months before the occurrence of the main event to 12 months after that. The main event $M_{N}=7.3$ is marked with a red star and the colored lines indicate the developmental stages, which include the black, pink, green, light and dark blue lines representing the first to the fifth order of energy accumulation stages for the aftershock sequence of Ezgeleh. The pink stars with the letter $\mathrm{F}$ represent foreshocks for the next large earthquake with $M_{N}=6.4$. According to Figure 8 , there is a gradual decrease initially in the magnitude values, after the pink F named points the magnitude of events are increasing up to the occurrence of the next large earthquake with $M_{N}=6.4$. If a straight line is drawn from the midpoint of the fifth order branch, an estimate of the minimum magnitude in the energy release stage is made. 


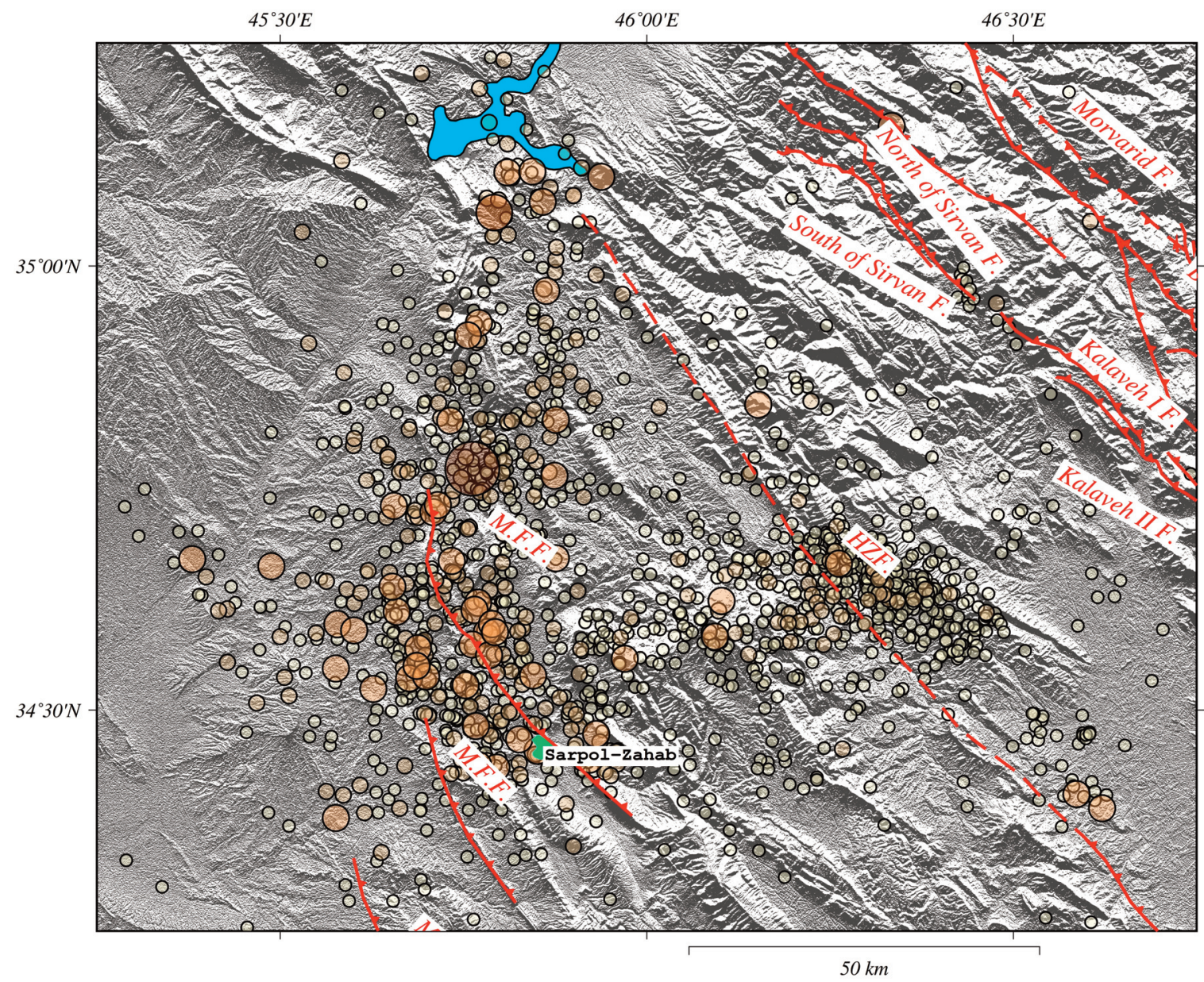

\section{Legend}

$\begin{array}{lll}\text { City } & \text { Major Fault } & \text { Local Network Earthquake (IRSC) } \\ & \text { Strike-Slip Fault } & \text { Probable Fault } \\ \text { Thrust Fault } & 1<=\mathrm{M}_{\mathrm{N}}<3 \\ 4<=\mathrm{M}_{\mathrm{N}}<5 \\ 5<=\mathrm{M}_{\mathrm{N}}<6 \\ 6<=\mathrm{M}_{\mathrm{N}}<7 \\ 7<=\mathrm{M}_{\mathrm{N}}\end{array}$

Figure 6. The distribution of locations of aftershocks of the Ezgeleh earthquake recorded during one year after the main shock occurance.

This predictive method can confirm the accuracy of our words to express that the F points could be considered as foreshocks of the subsequent large earthquake $M_{N}=6.4$.

Figure 9 presents a simple, convenient method according to Riga and Balocchi [2016], to identify the first relative minimum value after the main event $M_{N}=7.3$, the Ezgeleh earthquake. This minimum could be considered as the beginning of the secondary aftershocks in the sequence. The point is the first relative minimum event $M_{N}=4.1$ relative to the foreshock $M_{N}=3.7$.

Figure 10 presents how we identified the most energetic aftershocks directly triggered by the main event in the Ezgeleh sequence. According to Figure 10, the magnitude of the maximum point (Max 1 ) is approximately equal to the occurrence of the aftershock $M_{N}=4.6$ in the aftershock sequence of the Ezgeleh earthquake. This aftershock according to the relative minimum and maximum points and the branch structure could be referred to as the beginning of the first primary aftershock cycle in this sequence. The other most energetic events and cycles in this sequence could be obtained in the same way. 


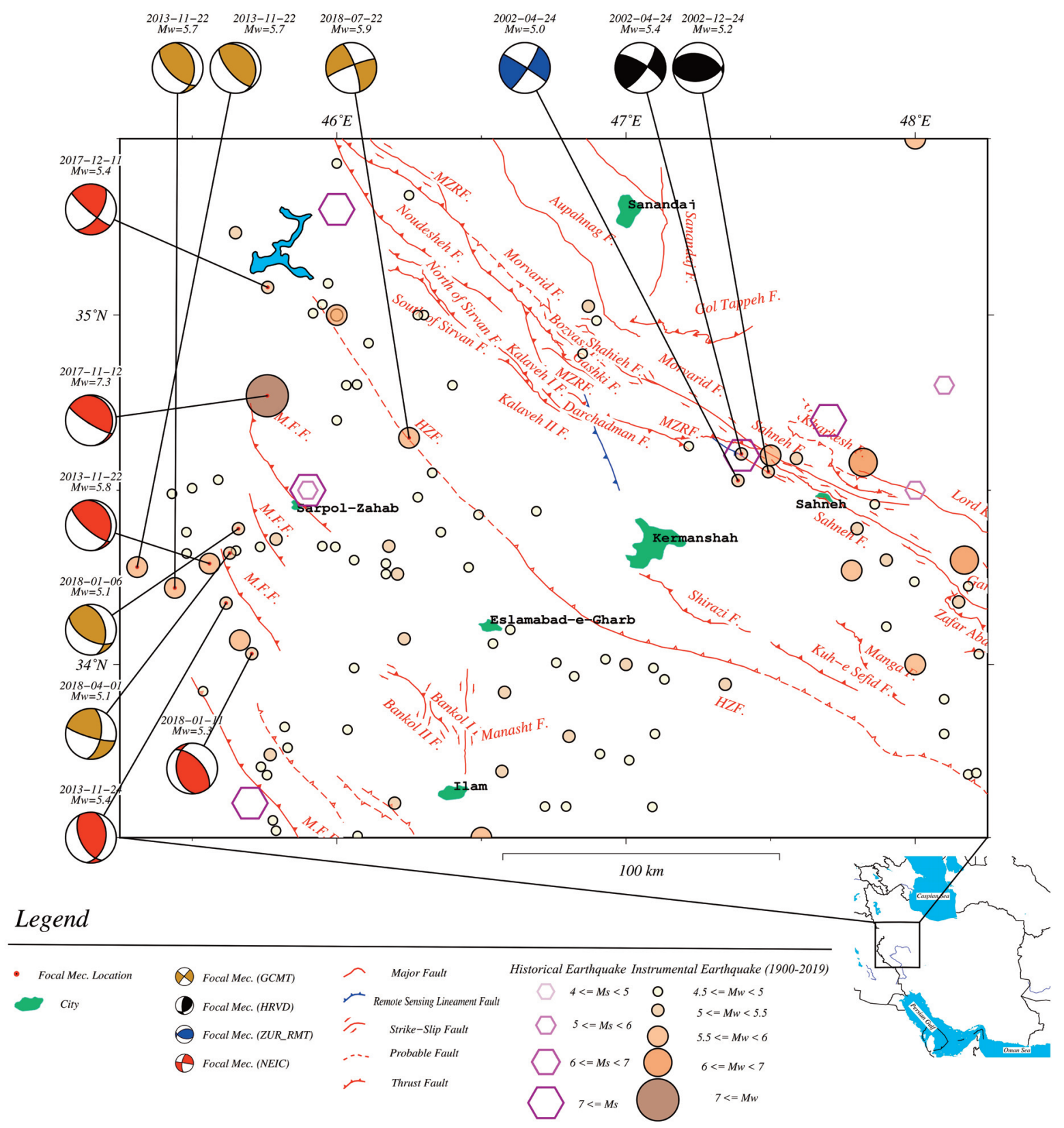

Figure 7. The seismicity map of the Ezgeleh region. The open hexagons represent the epicenters of historical events in the region. The circles indicate the epicenters of the instrumental recording to 2019. The focal mechanism extracted from GCMT, HRVD, ETH-Zurich and NEIC are shown for events equal or larger than $M_{W}=5.0$. 


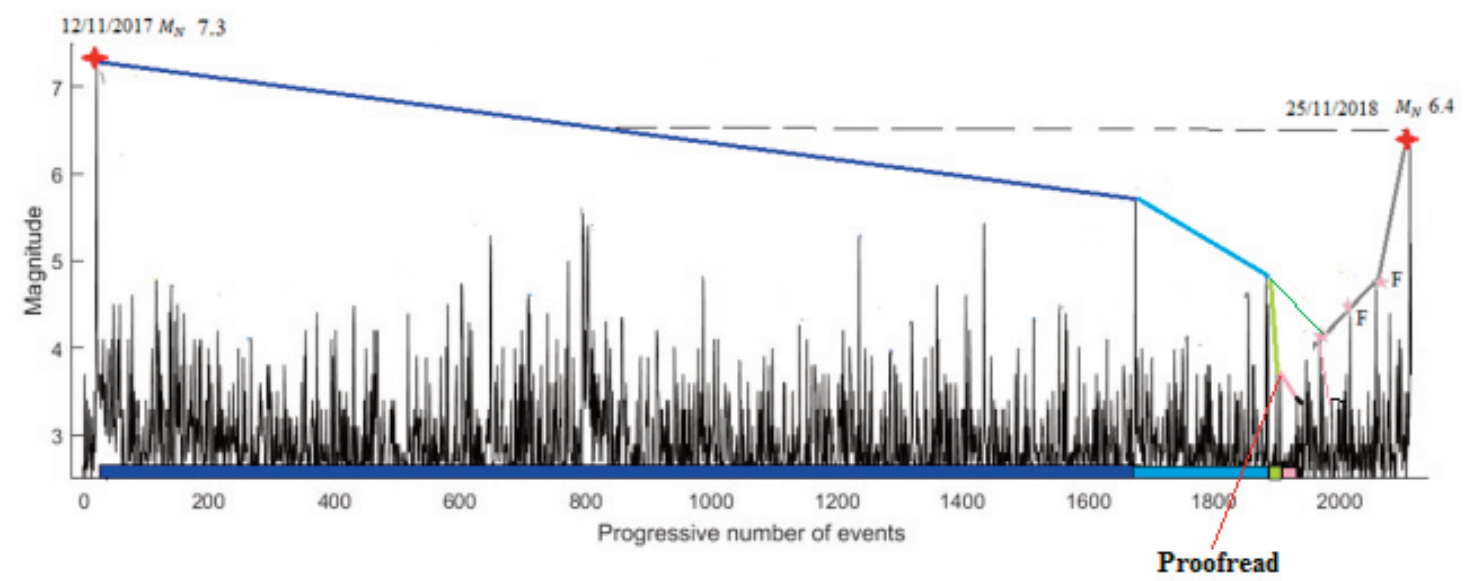

Figure 8. The branch structure of the Ezgeleh earthquake, the colored lines indicate the developmental stages, the pink stars indicated with letter $\mathrm{F}$ can be considered as foreshocks for $M_{N}=6.4$, according to Riga and Balocchi (2017).

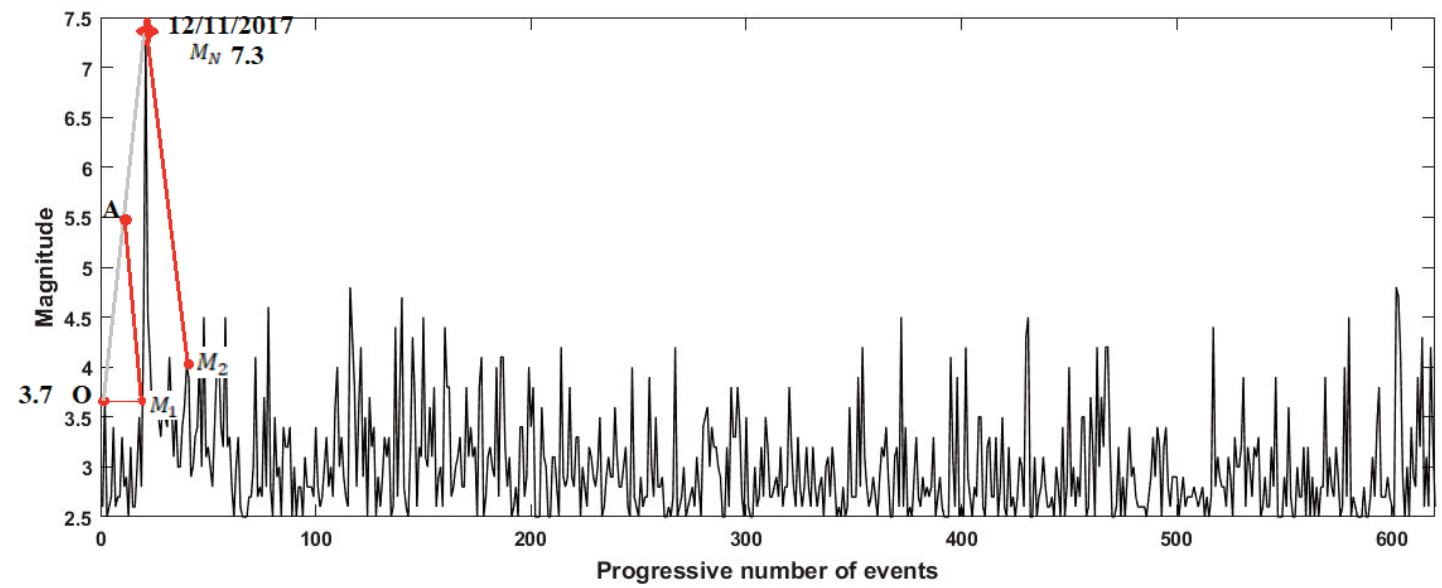

Figure 9. Determining the first minimum point $\left(M_{2}\right)$ which is formed after the main event $M_{N}=7.3$ relative to the minimum point $\left(M_{1}\right)$ before the main event in the Ezgeleh earthquake and the probable begin of the second seismic cycle.

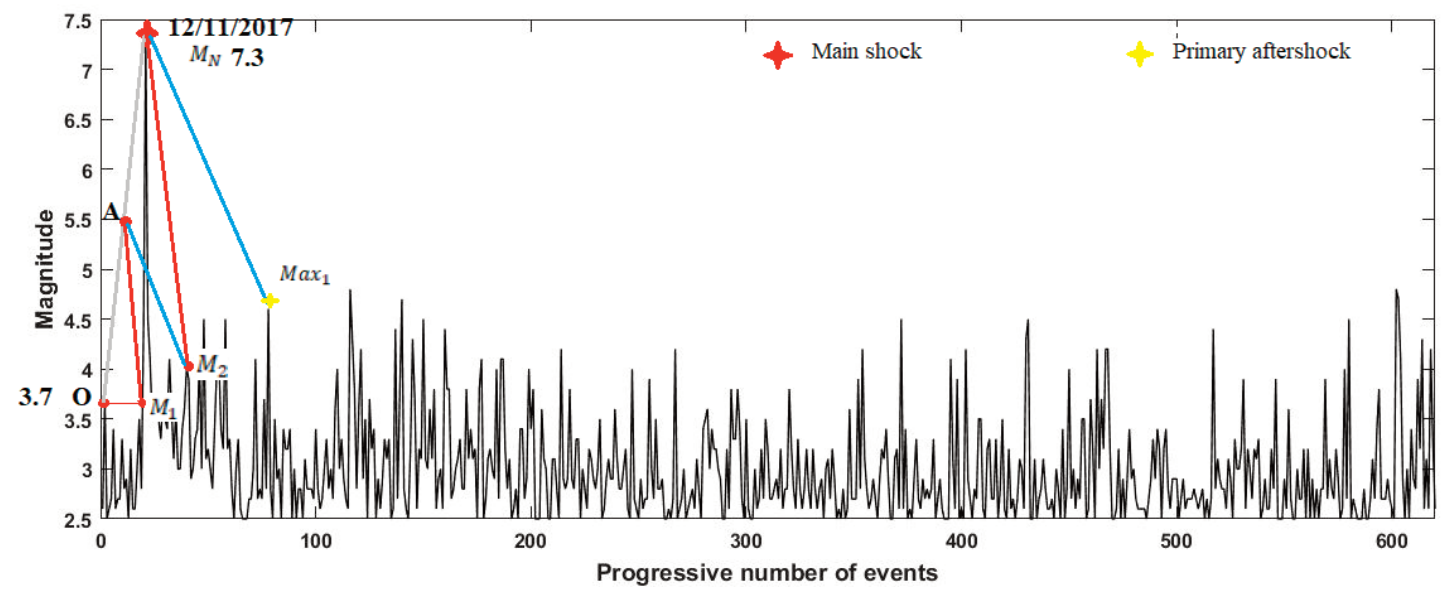

Figure 10. The procedure for determining primary aftershocks, first primary aftershock is formed after the main event $M_{N}$ $=7.3$ in the Ezgeleh earthquake. The red star indicates the Ezgeleh earthquake, the yellow star indicates the first most energetic aftershock. The blue lines point to the aftershock magnitude fluctuation range. 


\section{Mahdieh Lavasani and Elham Shabani}

\section{Conclusion}

Our study shows that the Kisslinger or the modified Omori models are the best-fitted decay rates to the aftershock sequences of selected large earthquakes in Iran. Although the Kisslinger exponential model shows poorly fitting with the data at the beginning of the sequences, but over time the Kisslinger decay rate shows better fitting with data compared to the Omori decay rate. This could be due to the $c$ parameter which controls the number of calculating events at the times immediately after the main event. Generally, in most of the studied earthquakes, the decay rate of the Omori in the short-term and the Kisslinger at the long-term show the best fitting with the sequence data. The behaviors of the two models in the long time are easily recognizable. The results show that the $p$ and $c$ parameters of the Omori law depend on the threshold magnitude and the chosen time window. And the $c$ parameter decreases with increasing the threshold magnitude, because the larger threshold magnitude value makes the smaller number of aftershocks to be eliminated at the beginning of the sequence in the catalog, therefore, the $c$ parameter decreases over time. However, we found no systematic pattern of changes for the $p$ parameter. The branch structure method [Riga and Balocchi, 2017] on the Ezgeleh earthquake sequence could successfully estimate the occurrence of an event with magnitude about 6.4, which its evidence was the occurrence of the earthquake $M_{N}=6.4$ on 25/11/2018.

Acknowledgements. The authors would like to acknowledge the Iranian Seismological Center (IRSC) for providing the earthquake database. We thank Dr. Serkan Öztürk and the anonymous reviewer for their constructive comments which helped improve this manuscript. We thank Dr. Giulio Riga and Dr. Paolo Balocchi for their valuable comments. Also, we acknowledge the financial support of University of Tehran for this research under grant number 28625/1/04.

\section{References}

Akaike, H. (1974). A new look at the statistical model identification, IEEE Trans. Autom. Control AC. 19, 716-723.

Ansari, S. (2017). Aftershocks properties of the 2013 Shonbe Mw 6.3 earthquake, central Zagros, Iran, J. Asian Earth Sci. 147,17-27.

Bath, M. (1965). Lateral inhomogenities in the upper mantle, Tectonophysics 2, 483- 514.

Bayrak Y. and S. Öztürk (2004). Spatial and temporal variations of the aftershock sequences of the 1999 İzmit and Düzce earthquakes, Earth Planets Space 56(10), 933-944.

Berberian, M. (1981). Active faulting and tectonics of Iran, In: H.K. Gupta and F.M. Delany (eds.), Zagros-HindukushHimalaya Geodynamics Evaluation, AGU,Washington, D.C., 33-69.

Das, S. and C.H. Scholz (1981a). Off-fault Aftershock Clusters Caused by Shear-stress Increase, Bull. Seismol. Soc. Am. 71, 5, 1669-1675.

Das, S. and C.H. Scholz (1981b). Theory of Time-dependent Rupture in the Earth, J. Geophys. Res. 86, 6039-6051.

Farahani, J.V. (2018). Statistical Properties of Aftershocks for Ahar-Varzeghan Twin arthquakes on 11 August 2012, NW Iran, and Investigation of Seismicity of North Tabriz Fault, International Journal of Geosciences 9, 106-118.

Gardner, J. K. and L. Knopoff (1974). Is the sequence of earthquake in Southern California, with aftershock removed, poissonian?, Bull. Seismol. Soc. Am. 64(5), 1363-1367.

Gasperini, P. and B. Lolli (2009). An empirical comparison among aftershock decay models, Phys. Earth Planet. Inter.175, 183-193

Gombert, B., Z. Duputel, E. Shabani, L. Rivera, R. Jolivet, and J. Hollingsworth (2019). Impulsive source of the 2017 MW = 7.3 Ezgeleh, Iran, earthquake, Geophys. Res. Lett. 46, 5207-5216, https://doi.org/10. 1029/2018GL081794.

Gutenberg, B. and C. Richter (1944). Frequency of earthquakes in California, Bull. Seismol. Soc. Am. 34, 185-188.

Hamaguchi, H. and A. Hasegawa (1970). An investigation on the aftershocks of the Tokachi-oki earthquake of 1968,

(1) Statistical study on magnitude distribution, Sci. Rep. Tohoku Univ. 5, 20, 85-105.

IRSC: The Iranian Seismological Center (http://irsc.ut.ac.ir)

Kisslinger, C. (1933). The stretched exponential function as an alternative model for aftershock decay rate, J. Geophys. Res. 98, 1913-1921.

Kisslinger, C. (1996). Aftershocks and Fault-Zone Properties. Advances in Geophysics, Vol.38, Academic Press, Inc., Cambridge, MA. 
Mignan, A. and J. Woessner (2012). Estimating the magnitude of completeness for earthquake catalogs, Community Online Resource for Statistical Seismicity Analysis.

Mirzaei, N., M. Gao, Y.T. Chen (1998). Seismic source regionalization for seismic zoning of Iran: major seismotectonic provinces, J. Earthq. Pred. Res. 7, 465-495.

Mogi, K. (1967a). Earthquakes and fractures, Tectonophysics 5, 35-55.

Mogi, K. (1967b). Foreshocks and earthquake swarms, Zisin, Ser. 2(20), 143-146.

Motoya, Y. and M. Kitagamae (1971). Report on the earthquake of southern part of Hokkaido on January 21, 1970, Geophys. Bull. Hokkaido Univ. 25, 141-151.

Mousavi, H., N. Mirzaei and E. Shabani (2014). A declustered earthquake catalog for the Iranian Plateau, Ann. Geophys. 57, 6 .

Nowroozi, A (1976). Seismotectonic provinces of Iran, Bull. Seism. Soc. Am. 66, 1249-1276.

Nuannin, P., O. Kulhánek and L. Persson (2012). Spatial and temporal characteristics of aftershocks of the December 26, 2004 and March 28, 2005 earthquakes off NW Sumatra, J. Asian Earth Sci. 46, 150-160.

Nur, A. and J.R. Booker (1971). Aftershocks caused by fluid flow? Science 175, 885-887.

Ogata, Y. (1983). Estimation of the parameters in the modified Omori formula for aftershock frequencies by the maximum likelihood procedure, J. Phys. Earth 31, 115-124.

Ommi, S., H. Zafarani and M. Zare (2016). Aftershock decay rates in the Iranian plateau, Pure Appl. Geophys. $173,2305-2324$.

Omori, F. (1894). On aftershocks, Rep. Imp. Earthq. Inv. Corn. 2, 103-138.

Öztürk, S., H. Çınar, Y. Bayrak, H. Karsli and G. Daniel (2008). Properties of aftershock sequence of the 2003 Bingöl, $\mathrm{MD}=6.4$, (Turkey) earthquake, Pure Appl. Geophys. 165(2), 349-371.

Öztürk, S. and Ş. Şahin (2019). A statistical space-time-magnitude analysis on the aftershocks occurrence of the July 21th, $2017 M_{W}=6.5$ Bodrum-Kos, Turkey, earthquake, J. Asian Earth Sci. 172, 443-457.

Ranalli, G. (1969). A statistical study of aftershock sequences, Ann. Geophys. 22, 359-397.

Reasenberg, P. A. and L.M. Jones (1989). Earthquake hazard after a mainshock in California, Science 243, 1173-1176.

Rezapour, M. and A. Mohsenpur (2013). The $2010 M_{W}=6.5$ Rigan, Iran, Earthquake aftershock sequence, Bull. Seismol.Soc. Am. 103, 3, 1793-1800.

Rezapour, M. (2016). The 2012 August $11 M_{W}=6.5$, 6.4 Ahar-Varzghan earthquakes, NW Iran: aftershock sequence analysis and evidence for activity migration, Geophys. J. Int. 204, 1191-1203.

Riga, G. and P. Balocchi (2016). Short-term earthquake forecast with the seismic sequence hierarchization method, Open J. Earthq. Res. 5, 79-96.

Riga, G. and P. Balocchi (2017). Aftershocks identification and classification, Open J. Earthq. Res. 6, 135-157.

Shcherbakov, R., D. L. Turcotte and J. B. Rundle (2004). A generalized Omori's law for earthquake aftershock decay, Geophys. Res. Lett. 31, L11613.

Shcherbakov, R., D. L. Turcotte and J. B. Rundle (2005). Aftershock statistics, Pure Appl. Geophys. 162, 1051-1076.

Scholz, C. H. (2002). The mechanics of earthquakes and faulting, 2nd ed. Cambridge university press.

Utsu, T. (1961). A statistical study on the occurrence of aftershocks, Geophys. Mag. 30, 521-605.

Utsu, T. (1962). On the nature of three Alaskan aftershock sequences of 1957 and 1958, Bull. Seismol.Soc. Am. 52, 279-297.

Utsu, T. (1969). Aftershocks and earthquake statistics (I)-Some parameters which characterize an aftershock sequence and their interrelation, J. Fac. Sci. Hokkaido Univ. Ser. VII, 2, 129-195.

Utsu, T., Y. Ogata and R. S. Matsu'ura (1995). The centenary of the Omori formula for a decay law of aftershock activity. J. Phys. Earth. 43(1), 1-33.

Van Stiphout, T., J. Zhuang and D. Marsan (2012). Seismicity declustering, Community Online Resource for Statistical Seismicity Analysis.

Walker, R.T., E. A. Bergman, J. R. Elliott, E. J. Fielding, A. R. Ghods, M. Ghoraishi, J. Jackson, H. Nazari, M. Nemati, B. Oveisi, M. Talebian and R. J. Walters (2013). The 2010-2011 South Rigan (Baluchestan) earthquake sequence and its implications for distributed deformation and earthquake hazard in southeast Iran, Geophys. J. Int. 193(1), 349-374.

Wiemer, S. and K. Katsumata (1999). Spatial variability of seismicity parameters in aftershock zones, J. Geophys. Res. 104(B6), 13, 135-151.

Wiemer, S. (2001). A Software Package to Analyze Seismicity: ZMAP, Seismol. Res. Lett. 72, 373-382. 


\section{Mahdieh Lavasani and Elham Shabani}

Williams, G. and D. C. Watts (1970). Non-symmetrical dielectric relaxation behavior arising from a simple empirical decay function, Trans. Faraday Soc., 66, 80-85.

Yamakawa, N., K. Kishio and K. Abe (1969). Spatial and time distribution of foreshocks and aftershocks of the earthquake near the southern Kurile Islands, Geophys. Mag. 34, 277-306.

*CORRESPONDING AUTHOR: Elham SHABANI,

Institute of Geophysics, University of Tehran, North Karegar Ave., Tehran, Iran, e-mail: eshabani@ut.ac.ir

๑) 2020 the Istituto Nazionale di Geofisica e Vulcanologia.

All rights reserved 